\title{
Study of Renal Toxicity in Wistar Rats Following the Action of Amphotericin B Solution Prepared under Extreme pH Conditions
}

\author{
Lamia Belkherroubi-Sari $^{1}$, Zahia Boucherit ${ }^{1}$, Kebir Boucherit ${ }^{1}$, Slimane Belbraouet ${ }^{2}$ \\ ${ }^{1}$ Laboratoire Antibiotiques, Antifongiques: Physico-Chimie, Synthèse et Activité Biologique, Université Abou Bekr Belkaïd, \\ Tlemcen, Algeria; ${ }^{2}$ École de Nutrition, Université de Moncton, New Brunswick, Canada. \\ Email: slimane.belbraouet@umoncton.ca
}

Received April 19 ${ }^{\text {th }}, 2011$; revised July 14 ${ }^{\text {th }}, 2011$; accepted July 21 ${ }^{\text {st }}, 2011$.

\begin{abstract}
Our study related to the renal toxicity of Wistar rats induced by solutions of amphotericin B prepared under extreme conditions of $\mathrm{pH}$ (5.4 and 10.8). The results obtained show that with $\mathrm{pH} 5.4$ of stock solution, urea and creatinin rate blood is not disturbed. These means that the renal function is not deteriorated by the amphotericin $B$. Furthers, treatment of animals infected by the yeast Candida albicans, with the solution of amphotericin B prepared at $p H 5.4$ and injected at $0.5 \mathrm{mg}$ of $\mathrm{AmB} / \mathrm{Kg}$ every 24 hours, seems to be effective.
\end{abstract}

Keywords: Amphotericin B, Renal Toxicity, Candida albicans

\section{Introduction}

Systemic fungal infections are a serious illness and their impact has been widespread in recent years. Despite the diversity of antifungal drugs to cure these infections, only the action of amphotericin B (AmB) spectrum covers most of the Candida organisms, which are a pathogenic species to humans [1,2]. Indeed, there are strains that are resistant to fluconazole [3] and 5-fluorocytosine [4]. In addition, the cost of the treatment is an important element in the therapeutic strategy as fluconazole, voriconazole, and caspofungin are significantly more expensive than AmB [5].

While AmB is relatively cheaper, it has a large number of adverse effects, with renal toxicity being the main reason for the restricted use [6]. This occurs when there is a cumulative dose of AmB in the serum. Thus, a cumulative dose of 3 to $4 \mathrm{~g}$ will induce irreversible renal impairment. On the other hand, at lower doses, renal failure becomes reversible after treatment cessation [7]. This toxicity is partially reduced with these antifungal lipid formulations. Unfortunately, their high cost (up to 90 times more expensive than Fungizone ${ }^{\circledR}$ ) limits greatly their use in clinics and particularly in poor countries [8]. AmB hence poses a serious toxicity problem in clinical practice, and it is essential to find a way for increasing the therapeutic index.
To overcome this problem, some solutions have been proposed, including heating Fungizone ${ }^{\circledR}$ at $70^{\circ} \mathrm{C}$ for 20 minutes $[9,10]$, which allows a reduction of toxicity while retaining the effectiveness. More recently Mariné and coll. [8] and Espada and coll. [11] proposed a polyaggregate AmB obtained by the solubilization of the antifungals in a solution containing sodium desoxycholate. However, unlike Fungizone ${ }^{\circledR}$, it is not at $\mathrm{pH}$ 7.4, thereby reducing the in vivo toxicity of the antifungal. A previous study conducted in vitro on the effect of $\mathrm{pH}$ [12] showed that AmB solubilized at pH 5.4 and 10.8 induce a significant reduction of toxicity in erythrocytes while preserving the antifungal effectiveness in Candida albicans. For this reason, the authors considered it essential to observe the effect of $\mathrm{pH}$ on the selective toxicity of AmB in Wistar rats.

\section{Material and Methods}

\subsection{Animals}

Male Wistar rats (200 g) were housed in groups of six in plastic cages in 12-hour dark-light cycle animal facility at controlled temperature $\left(25^{\circ} \mathrm{C}\right)$ and humidity $(70 \%)$. Water and food were unrestricted throughout the study.

\subsection{Candida Strain}

Candida albicans ATCC 10231 (444 IP Institut Pasteur, 
Paris) was used in all experiments and stored at $4^{\circ} \mathrm{C}$ in Sabouraud agar.

\subsection{Antifungal Solutions}

Pure AmB (SIGMA) was dissolved in dimethyl sulfoxide (DMSO) at a concentration of $10^{-2} \mathrm{M}$. From this stock solution, antifungal solutions were prepared at $10^{-4} \mathrm{M}$ using a carbonate/bicarbonate buffer $(10 \mathrm{mM})$, which had a pH of 10.8, and an acetic acid/acetate buffer (100 $\mathrm{mM}$ ), which had a $\mathrm{pH}$ of 5.4. These solutions were kept at ambient temperature and out of light for 20 min before use.

\subsection{Drug Administration}

AmB at $1 \mathrm{mg} / \mathrm{kg}$ was administered via lateral vein tail and samples of the blood were collected from the orbital sinus of the same animal. Urea and creatinin was analyzed by an auto-analyzer Beckman CX9. For statistical analysis, ANOVA1 and Student's t-test (Minitab 12.2) were used at $p<0.05$.

\subsection{Infection Study}

The yeast strain was grown for 18 hours at $37^{\circ} \mathrm{C}$ in the Sabouraud liquid, washed twice with a phosphate buffer saline (PBS pH: $7.510 \mathrm{mM}, \mathrm{NaCl} 150 \mathrm{mM}$ ), and diluted in the same buffer to the desired density of $10^{8} \mathrm{cell} / \mathrm{mL}$.

Disseminated infection of $C$. albicans in the rats was achieved by the injection of $2 \times 10^{6} \mathrm{cell} / \mathrm{mL}$ via the intraperitoneal method 72 hours prior to starting the drug therapy (Espada and al., 2008). The number of $\mathrm{cfu} / \mathrm{mL}$ in blood was determined by a plate dilution method using the Sabouraud agar and counting colonies after 24 - 48 hours of incubation at $37^{\circ} \mathrm{C}$.

\section{Results}

Nephrotoxicity is achieved in patients treated with AmB, though the drug remains one of the most effective solutions for the treatment of invasive fungal infections [13]. It should be recalled that urea is derived from the destruction of proteins and is completely filtered by the glomeruli. Creatinin in blood, a constituent of muscle protein, is eliminated by the kidneys and is not converted to urea by non-renal factors. Determination of urea and creatinin in the blood reflect the renal function.

Compared to the physiological $\mathrm{pH}$ of 7.4 in rats when injected up to $3 \mathrm{~mL}$ (maximum volume that can be introduced in a rat), there was no change in the blood $\mathrm{pH}$ of the control animals; is kept constant at pH $7.6 \pm 0.02$.

\subsection{Evaluation of Acute Renal Toxicity}

When the rats were treated by the buffer solution also (pH 5.4 or 10.8), the antifungal solution showed no be- havior disorder (aggressiveness or asthenia) for $1 \mathrm{mg}$ of $\mathrm{AmB} / \mathrm{kg}$. A single injection of AmB solution, solubilized at $10^{-4} \mathrm{M}$ in carbonate bicarbonate $(10 \mathrm{mM})$ to $10.8 \mathrm{pH}$ buffer, disturbed renal parameters (urea and creatinin), and these disruptions persist beyond by one-week followup (Figure 1). However, the single injection of a solution of AmB solubilized at $10^{-4} \mathrm{M}$ in acetate/acetic acid buffer (100 mM), pH 5.4 at $1 \mathrm{mg} / \mathrm{kg}$, did not induce any significant disruption of the renal parameters, urea and creatinin, in Wistar rats (Figure 2). It seems then that the prepared solution AmB of pH 5.4 is better tolerated than that prepared at $\mathrm{pH} 10.8$ on a renal plan following a sin-
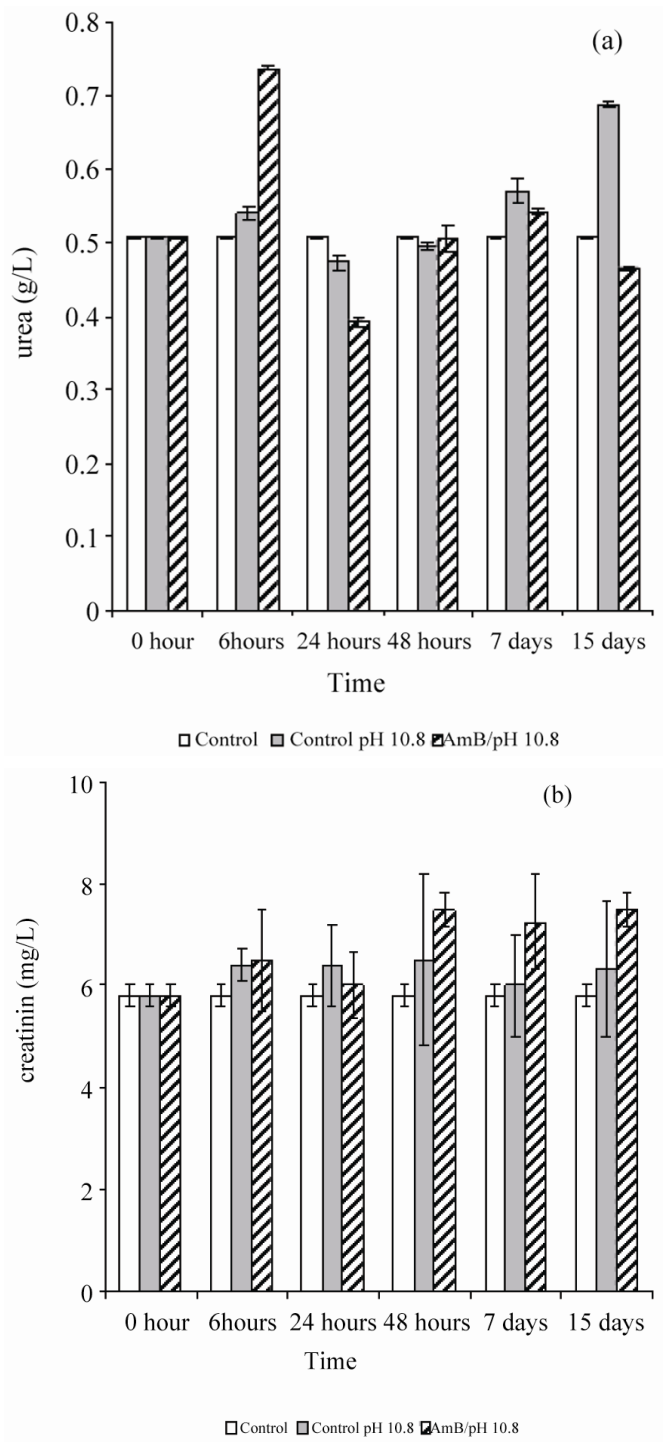

Figure 1. Effect of a single injection of a solution of AmB solubilized at $10^{-4} \mathrm{M}$ in carbonates/bicarbonate buffer $\mathrm{pH}$ $10.8(10 \mathrm{mM})$, at a rate of $1 \mathrm{mg} / \mathrm{kg}$, on the blood parameters (urea and creatinin) in Wistar rats. 

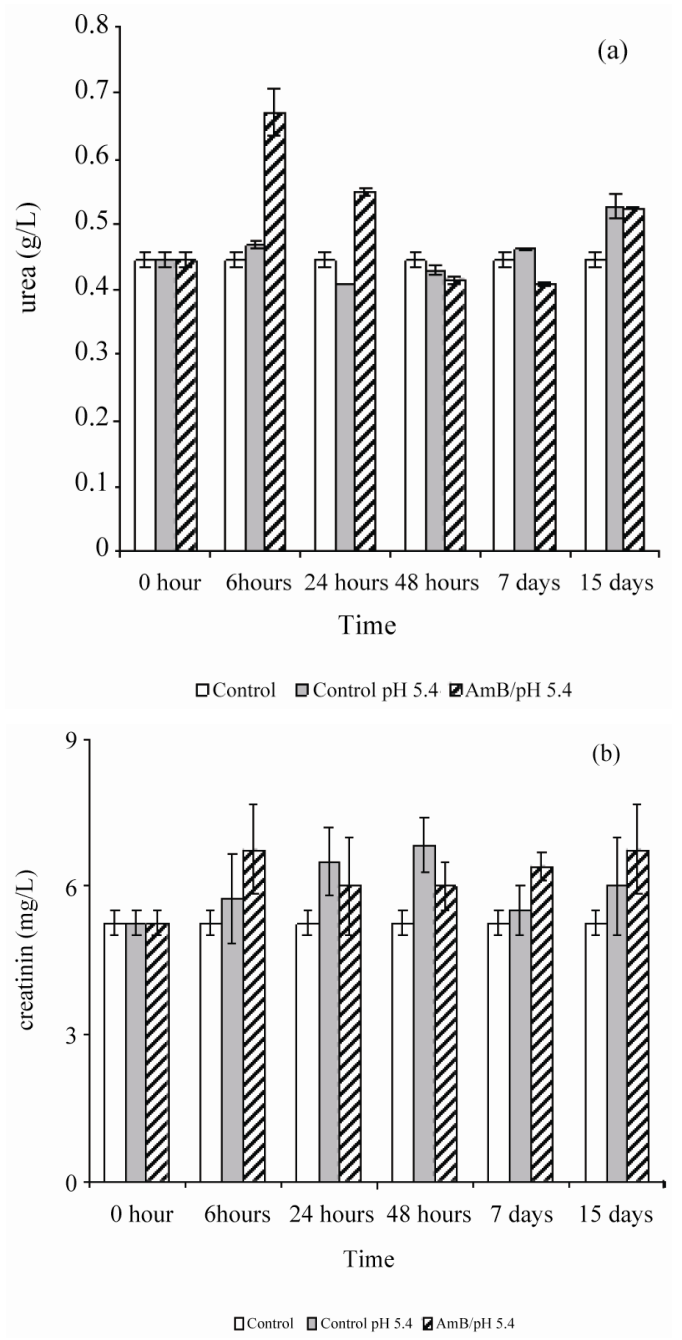

Figure 2. Effect of a single injection of a solution of AmB solubilized with $10^{-4} \mathrm{M}$ in acetic acid/ acetate buffer $\mathrm{pH} 5.4$ $(100 \mathrm{mM})$ at a rate of $1 \mathrm{mg} / \mathrm{kg}$, on the blood parameters (urea and creatinin) in healthy Wistar rats.

gle injection $1 \mathrm{mg}$ of $\mathrm{AmB} / \mathrm{kg}$.

In the second step, the authors assessed the toxicity of the AmB solution solubilized at $10^{-4} \mathrm{M}$ in the acetate/ acetic acid buffer $(100 \mathrm{mM})$ at $\mathrm{pH} 5.4,1 \mathrm{mg} / \mathrm{kg}$, due to repeated injections for 48 hours until the animal died. Every 48 hours, follow-up is done on the same rats from the beginning to the end of the experiment. The first collection is done 24 hours after the first injection. From the second injection, aggression and asthenia rats are used for batch control and test. After the fourth injection, four rats of the six tested groups died while two other lots (experimental and control) were alive. 100\% lethality test batch was achieved after the sixth injection. The authors note that three injections of AmB solubilized $10^{-4} \mathrm{M}$ solutions in acetate/acetic acid (100 mM) of pH buffer 5.4,
$1 \mathrm{mg} / \mathrm{kg}$ every 48 hours do not cause significant disturbance in the renal parameters (urea and creatinin) (Figure 3).

\subsection{Evaluation of the Effectiveness of the Solution of Amphotericin B Prepared for pH 5.4 in Wistar Rats Infected by Candida albicans}

After inoculation of a lot of healthy male Wistar rats with $0.2 \mathrm{~mL}$ suspension of $10^{8}$ cell $/ \mathrm{mL}$ of Candida albicans,
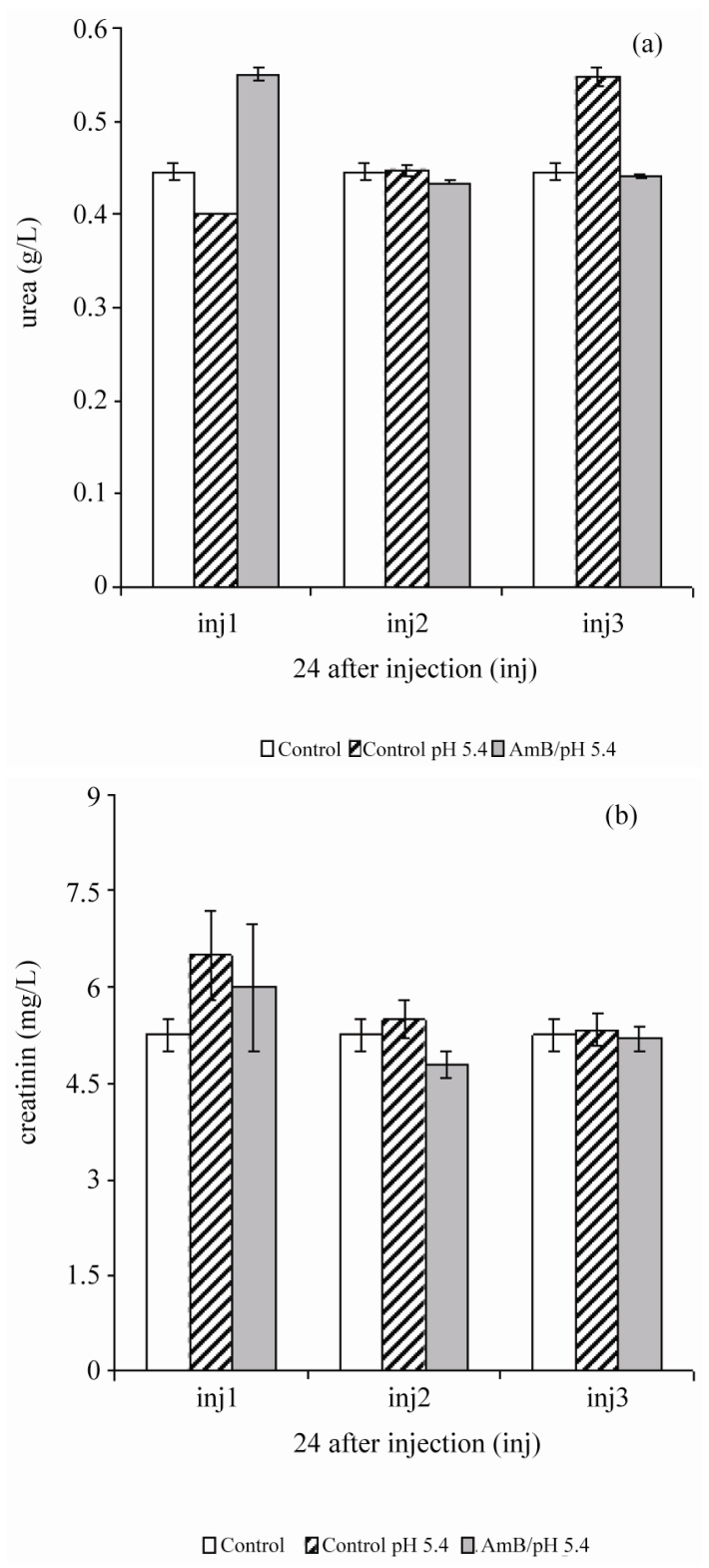

Figure 3. Effect of repeated injections of a solution of AmB solubilized with $10^{-4} \mathrm{M}$ in acetic acid/ acetate buffer $\mathrm{pH} 5.4$ $(100 \mathrm{mM})$ at a rate of $1 \mathrm{mg} / \mathrm{kg}$, on the blood parameters (urea and creatinin) in healthy Wistar rats. 
the yeast appears in the blood after 48 hours. The rate of yeast in blood animals attains $1.65 \times 10^{5} \mathrm{cfu} / \mathrm{mL}$ after 72 hours of incubation and remained constant for 10 days (240 hours) (Figure 4). On the other hand, the authors note a loss of appetite and a decrease in energy in the rats, 72 hours after the inoculation of yeast, which coincides with the time of yeast propagation in the blood. The animals were still alive during the 16th day of follow-up. In addition, the inoculation of the yeast induced disruption of the creatinin, reflecting renal disruption 72 hours after inoculation. This is consistent with the onset of yeasts in blood (unrepresented results).

The results of the blood test obtained on every injection of the antifungal solution prepared at $\mathrm{pH} 5.4,1 \mathrm{mg}$ of $\mathrm{AmB} / \mathrm{kg}$, show that the number of yeast is greatly reduced due to repeated injections of the solution at $\mathrm{pH} 5.4$ AmB. Indeed, the rate of yeast passes from $2 \times 10^{7}$ $\mathrm{cfu} / \mathrm{mL}$ to $5 \times 10^{2} \mathrm{cfu} / \mathrm{mL}$ after the last injection. However, the treatment could not be continued because total lethality was observed after the sixth antifungal solution injection. On the other hand, when dealing with the animals injected every 24 hours with $0.5 \mathrm{mg}$ AmB kg (Figure 5), total efficiency was observed (it should be noted that in this last condition experimental animals undergo seven injections).

\section{Discussion}

Testing in vivo revealed that the injection of a solution of amphotericin B at $1 \mathrm{mg} / \mathrm{kg}$, solubilized at $10^{-4} \mathrm{M}$, pH 5.4, does not cause significant blood parameter disturbances in renal urea creatinin or liver alkaline phosphatase/ transaminase (unrepresented results) in Wistar rats. However, at $\mathrm{pH} 10.8$, it induces significant serum urea, crea-

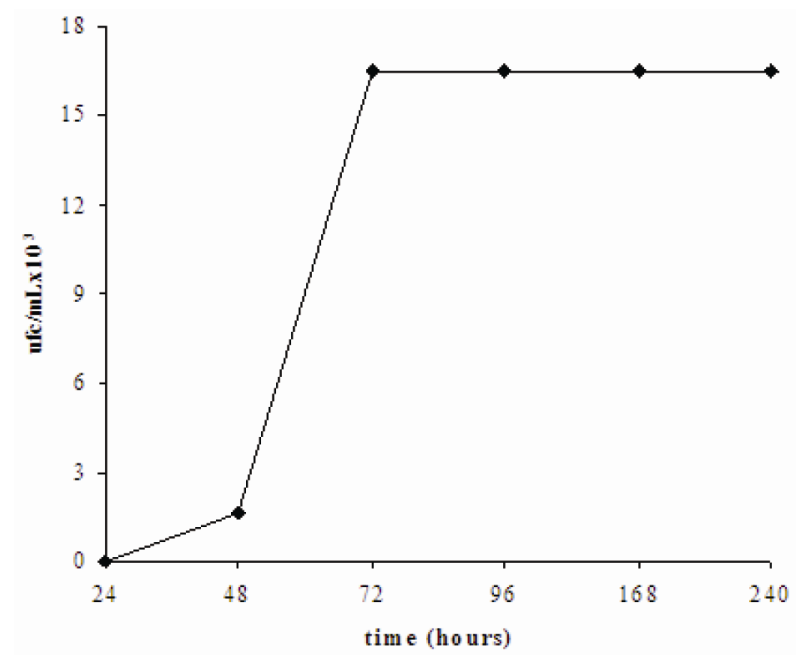

Figure 4. Concentration of yeasts in blood of healthy Wistar rats after inoculation of yeasts.

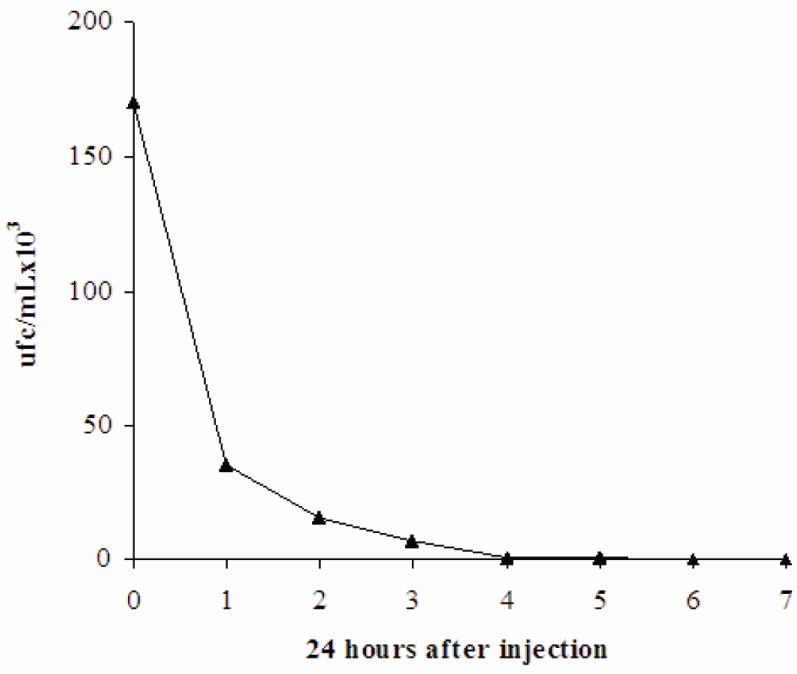

Figure 5. Concentration of yeasts in blood of Wistar rats infected, after treatment with $\mathrm{AmB}(0.5 \mathrm{mg} / \mathrm{kg}$ ) (solution dissolved at pH 5.4).

tinin, alkaline phosphatase, and transaminase modification. In addition, three injections of solutions of AmB, of pH 5.4, every 48 hours (at $1 \mathrm{mg} / \mathrm{kg}$ ), do not seem to disturb renal and hepatic parameters in Wistar rats to batch control.

For the treatment of Wistar rats infected with the yeast Candida albicans, the solution of AmB, solubilized at $10^{-4} \mathrm{M}$ in buffer acetate/acetic acid (100 mM) pH 5.4, 1 $\mathrm{mg} / \mathrm{kg}$ every 48 hours, does not prove effective. The blood is negative $(0 \mathrm{cfu} / \mathrm{mL})$ in only $50 \%$ of rats after 9 days. However, in the remaining $50 \%$, the rate of yeast is very low $\left(5 \times 10^{3} \mathrm{cfu} / \mathrm{mL}\right)$ to start inoculum $\left(1.7 \times 10^{5}\right)$. The treatment of animals by injection, repeated every 24 hours at $0.5 \mathrm{mg} \mathrm{AmB}$ per $\mathrm{kg}$, seems to be totally effective after 7 injections (negative blood). Ultimately, the preparation of a new formulation of AmB from a stock solution buffered at $\mathrm{pH} 5.4$ seems to be a possible solution among others. It has the advantage of being inexpensive, easy to access, and allows an increase in the

\section{REFERENCES}

[1] D. Sanglard and F. C. Odds, "Resistance of Candida Species to Antifungal Agents: Molecular Mechanisms and Clinical Consequences," Lancet Infectious Disease, Vol. 2, No. 2, 2002, pp. 73-85. doi:10.1016/S1473-3099(02)00181-0

[2] M. M. Canuto and F. G. Rodero, "Antifungal Drug Resistance to Azoles and Polyenes," Lancet Infectious Disease, Vol. 2, No. 9, 2002, pp. 550-63.

[3] D. A. Said, E. Anaissie, O. Uzun, H. Pinzkowzki and S. Vartivarian, "The Epidemiology of Hematogenous Candidiasis Caused by Different Candida Species,” Clinical 
Infectious Disease, Vol. 24, No. 6, 1997, pp. 1122-1128. doi:10.1086/513663

[4] A. H. Groll and J. C. Gea-Banacloche, "Clinical Pharmacology of Antifungal Compounds," Infectious Disease Clinics Of North America, Vol. 17, No. 1, 2003, pp. 159-191.

[5] A. Kettani, Z. H. Belkhadir, A. Mosadik, A. Faroudy, A. Ababou, A. Lazreq and A. Sbihi, "Traitement Antifongique des Candidoses Systémiques en réAnimation,” Journal de Mycologie Médicale, Vol. 16, No. 1, 2006, pp. 16-25.

[6] J. P. Adler-Moore, J. A. Olson and R. T. Proffitt, “Alternative Dosing Regimens of Liposomal Amphotericin B (AmBisome) Effective in Treating Murine Systemic Candidiasis," Journal of Antimicrobial Chemotherapy, Vol. 54, No. 6, 2004, pp. 1096-1102. doi:10.1093/jac/dkh460

[7] B. Blanchet, E. Huet, A. Astier and A. Hulin, "Suivie Thérapeutique des Médicaments Antifongiques. Pharmacocinétique des Médicaments Infectieux," Revue Française des Laboratoires, Vol. 2004, No. 365, 2004, pp. 39-47.

[8] M. Mariné, R. Espada, J. Torrado, F. J. Pastor and J. Guarro, "Efficacy of a New Formulation of Amphotericin B in a Murine Model of Disseminated Infection by Candida Glabrata,” Journal of Antimicrobial Chemotherapy, Vol. 61, No. 4, 2008, pp. 1-4.
[9] F. Gaboriau, M. Cheron, C. Petit and J. Bolard, "Heat-Induced Superaggregation of Amphotericin B Reduces Its in Vitro Toxicity: A New Way to Improve Its Therapeutic Index,” Antimicrobial Agents and Chemotherapy, Vol. 41, No. 11, 1997, pp. 2345-2351.

[10] C. Petit, M. Cheron, V. Joly, J. M. Rodrigues, J. Bolard and F. Gaboriau, "In-Vivo Therapeutic Efficacy in Experimental Murine Mycoses of a New Formulation of Deoxycholate-Amphotericin B Obtained by Mild Heating,” Journal of Antimicrobial Chemotherapy, Vol. 42, No. 6, 1998, pp. 779-785. doi:10.1093/jac/42.6.779

[11] R. Espada, S. Valdespina, M. A. Dea, G. Molero, M. P. Ballesteros, F. Bola and J. J. Torrado, "In Vivo Distribution and Therapeutic Efficacy of a Novel Amphotericin B Poly-Aggregated Formulation," Journal of Antimicrobial Chemotherapy, Vol. 61, No. 5, 2008, pp. 1-7.

[12] L. Belkherroubi-Sari, Z. Boucherit, M. Chéron, K. Boucherit, M. Benyoucef and S. Belbraouet, "Modulation of the Polyene Antibiotic Amphotericin B Selective Toxicity by $\mathrm{pH}$ Change of the Stock Solutions," African Journal of Microbiology Research, Vol. 2, 2008, pp. 242-246

[13] M. Kleinberg, "What Is the Current and Future Status of Conventional Amphotericin B?” International Journal of Antimicrobial Agents, Vol. 27, No. 1, pp. 12-16. doi:10.1016/j.ijantimicag.2006.03.013 